\title{
Evolución de los hornos de cal a través del tiempo en las ciudades de Canarias
}

\author{
The Evolution Over Time of Lime Kilns in the Cities of the Canary Islands
}

\author{
Jorge L. Manzano Cabrera* \\ Universidad de Las Palmas de Gran Canaria \\ https:/ / orcid.org/0000-0002-6741-5564 \\ jmancab7@gmail.com \\ Francisco M. Mireles Betancor \\ Cabildo de Gran Canaria, FEDAC \\ https:/ / orcid.org/0000-0003-1755-2306 \\ mireles.paco@gmail.com
}

Recibido: 12/07/2020; Revisado: 12/12/2020; Aceptado: 17/12/2020

\begin{abstract}
Resumen
En los años veinte del siglo xx, se solicitaron permisos para edificar hornos de cal en varias ciudades de Canarias, habiendo sufrido alteraciones en su situación y estado en el transcurso del tiempo. Próximos a los recursos (canteras, madera, u obras), o zonas accesibles y bien comunicadas (puertos, caminos, etc.), estas estructuras de combustión han sido ocupadas por el tejido urbano, llegando a desaparecer o, al contrario, integrarse en las urbes dentro de la malla constructiva civil. Este artículo analizará el patrimonio industrial de la cal mediante documentación bibliográfica, planimétrica y fotografía aérea, tanto histórica como reciente.
\end{abstract}

Palabras clave: Horno reverbero, cal, tejido urbano, presión urbanística, patrimonio industrial.

\begin{abstract}
In the 1920s, permits to build lime kilns were sought in several cities in the Canary Islands, after undergoing changes to their locations and conditions over time. Whether situated close to resources (quarries, wood or worksites), or accessible and well-communicated areas (ports, roads, etc.), these combustion structures have been woven into the urban fabric, fully disappearing or contrariwise becoming integrated into cities as part of the civil construction grid. This article analyses the industrial
\end{abstract}

*Autor de correspondencia / Corresponding author.

Copyright: (C) 2021 ULPGC. Este es un artículo de acceso abierto distribuido bajo los términos de la licencia Creative Commons Atribución-NoComercial-SinDerivar (by-nc-nd) Spain 3.0. 
Evolución de los hornos de cal a través del tiempo en las ciudades de Canarias

heritage of lime by means of bibliographic, planimetric and aerial-photographic documentation, both historical and recent.

Keywords: Reverberatory Furnace, Lime Kilns, Urban Fabric, Urban Pressure, Industrial Heritage.

\section{INTRODUCCIÓN}

Durante el proceso de colonización de las islas, y ante la acuciante necesidad de abrigar a la nueva población, las primeras viviendas que se construían se realizaron con materiales inflamables (QUINTANA, 2010:37), muchas de ellas fueron devastadas por incendios catastróficos, tal como sucedió en la Villa de Arriba de La Laguna (LoBo, 2004: 275).

A partir del siglo $\mathrm{xVI}$, se efectúa un cambio progresivo y paulatino en los sistemas constructivos, forzados por el empleo de materiales como la piedra, el barro y otros tipos de morteros. Se publicaron ordenanzas desde los organismos públicos, como las de 1531 en Gran Canaria (Hernández et al., 2020: 8), que daban instrucciones sobre las formas de edificabilidad (Lово, 2004: 275). Ya desde los albores de los primeros siglos tras la conquista del Archipiélago, se introduce la cal como un elemento base en los albeos y revocos (QUiNTANA, 2015: 236), de viviendas señoriales y solariegas de la población civil y eclesiástica. Además, la cal tuvo otra serie de usos más comunes de amplia difusión, como fue su aprovechamiento en los ingenios azucareros para el blanqueo del producto final; la conservación e higienización del agua almacenada en aljibes para uso doméstico (GIL et al., 2006:91-94) o, tras el fallecimiento de una persona, acelerar el proceso putrefacción, evitando así la propagación de enfermedades (MIRELES, 1996: 43).

Entre los siglos XVI al xVIII, los hornos de cal se difunden por el Archipiélago $\mathrm{y}$, con ella, los oficios artesanos asociados, que mantuvieron una estructura casi gremial, heredada del Medievo (HernÁNDEZ et al., 2020: 2). El uso progresivo de esta materia prima es más evidente en aquellas islas que, como Fuerteventura, que poseía una materia prima de calidad y escaso arbolado, pues «la demanda constructiva en la ciudad se basaba en la cal, piedras y cantería, siendo estos tres elementos el centro de atención de los regidores» (HerNández et al., 2020: 8).

Y se registra que «en el primer tercio del siglo XVII se localizaron 72 hornos de cal en la isla [de Gran Canaria], (...), destacando los construidos en las zonas de Hornos del Rey en Jinámar, (Telde), la montaña de San Francisco (Las Palmas de Gran Canaria), barranco de Guadalupe (Moya), los de Cuevas de Torado, en el barranco de La Ballena, San Cristóbal o Vega de San Lázaro y Tafira, en Las Palmas de Gran Canaria, Bañaderos (Arucas), Valle de Agaete o el del barranco de Guía» (Hernández et al., 2020: 11).

Las obras de grandes proporciones requirieron que existiera materia prima en las proximidades, por lo que era habitual encontrar un horno de cal de fácil acceso en un perímetro no muy alejado y bien comunicado por tierra o, por el contrario, los ubicamos cercanos a la madera o a la cantera de extracción de caliche, o calera. Otro factor, cuando la cal ha sido deficitaria, se situaron los 
hornos próximos al mar, para así traer por vía marítima y en bruto, los bloques de cal, documentándose para Gran Canaria un numeroso conjunto de hornos a pocos metros de la línea de costa. ${ }^{1}$

A partir del siglo xIX el crecimiento de las ciudades principales, con el consiguiente aumento de la población y la expansión del comercio en las últimas décadas, trajo que algunos hornos quedaran amenazados por el incremento de la trama urbana, que tuvo que adaptar los alineamientos de edificaciones a la presencia de estas industrias. Otros, desgraciadamente, sufrieron el derribo para ser suplantados por viviendas. Sin embargo, se ha constatado, a través de la documentación, que una tipología de horno, de mayor capacidad de producción, se instaló en zonas próximas a los puertos y áreas de mayor actividad comercial, como fueron los hornos reverberos, que se adaptaron, por su tipología a la normativa municipal existente a finales del XIX.

La presencia de los hornos reverberos en Canarias ha pasado prácticamente desapercibida para la investigación y es, a través del rastreo de la toponimia cuando se ha podido sondear los vestigios de este patrimonio industrial, en el contexto del paisaje urbano. Actualmente, se posee una escasa información sobre los hornos de cal en los entornos y en el interior de las ciudades del Archipiélago, pues estas infraestructuras fueron demolidas en los sucesivos procesos de expansión urbanística, tras caer en desuso por su poca rentabilidad con la generalización del cemento. Ha sido el rastreo de proyectos, planos históricos, fotografías antiguas, etc., como nos hemos podido acercar a su pasada existencia. Los pocos restos que aún perduran sobre áreas abandonadas del suelo rústico, menos antropizado, y en los perímetros de las ciudades, son los que nos dan la pauta para investigarlos. Como ejemplo ha servido el horno llamado de «los Betancores», en Barranco Seco, que tiene una superficie de unos 150 metros cuadrados. Es de planta rectangular y se encuentra ejecutado con fábrica de muros «a cajón», de morteros de cal y piedra, salvando un desnivel de 11 metros de altura. Formalmente presenta un frente ligeramente adelantado de unos 16 metros de longitud en el que se sitúa la puerta de carga de la hornilla por el que se extrae la cal viva y, en los paramentos más retrasados están los huecos, a un nivel superior, por los que se llenaba de combustible. Interiormente el horno ocupa una superficie circular de 2,85 m de diámetro, revestida la estructura de ladrillos refractarios macizos que se mantienen aún adosados al terreno (Manzano, 2015: 245).

1 FEDAC, 2002, Carta Etnográfica de Gran Canaria (2002), FEDAC, Cabildo de Gran Canaria [en línea]. Disponible en: https:/ / cartaetnograficagc.org [Consulta: 12/07/2020]. 


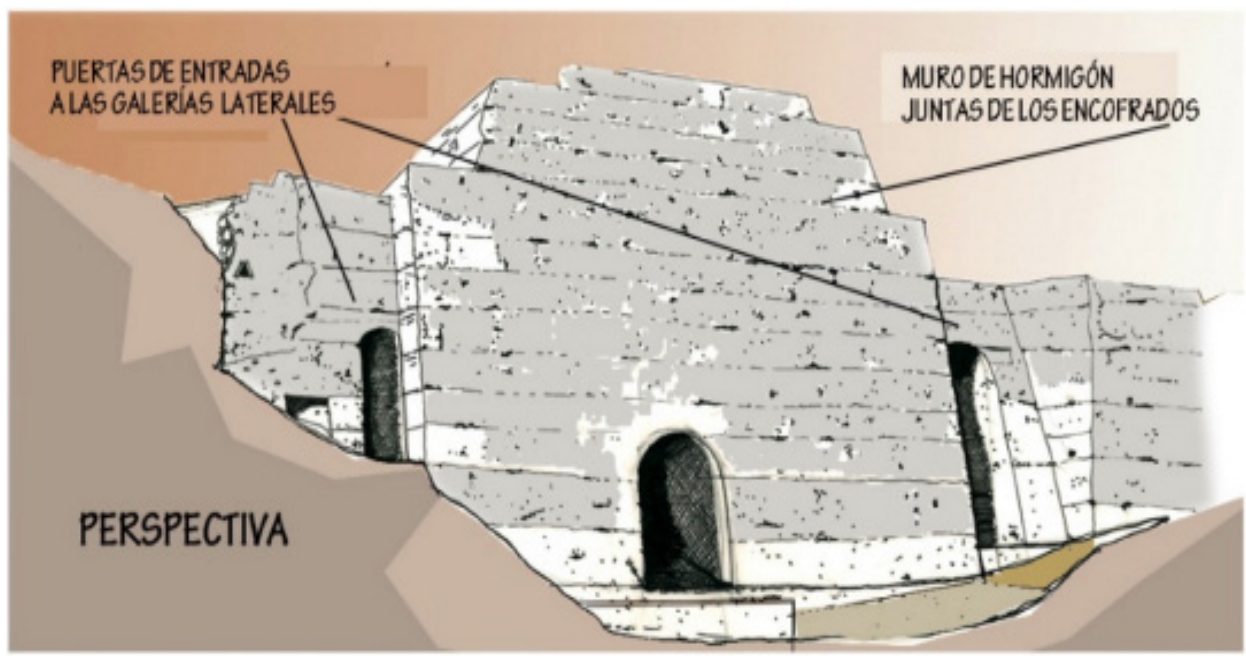

Figura 1. Perspectiva del horno de cal de Barranco Seco en Las Palmas de Gran Canaria. Fuente: Manzano (2015).

Por tanto, a partir de la reflexión suscitada por el estudio de campo y la documentación consultada de estas estructuras de combustión, se ha intentado en este trabajo desentrañar aspectos fundamentales como la ubicación espacial de los hornos, principalmente los de reverbero, en las ciudades canarias; así como diferenciar las diversas tipologías y cómo se han ido adaptando a cada entorno; evaluar el estado de conservación de los restos que aún perviven; valorar su trascendencia como elementos del patrimonio industrial; y rescatar la memoria de unas construcciones que han dado carácter propio al ambiente donde estuvieron enclavadas y que podemos rastrear a través de la toponimia y la documentación.

La progresiva pérdida de las fábricas de la cal dentro de la trama urbana ha obligado a buscar su existencia en archivos, en de las solicitudes de obras para la construcción de hornos de cal. El Archivo Histórico Provincial de Las Palmas custodia las diligencias de estas peticiones, siendo los expedientes del arquitecto Laureano Arroyo y del ingeniero Julián Cirilo Moreno, quienes mostraban una mayor producción de proyectos al respecto. Aun así, en la ciudad de Las Palmas de Gran Canaria existen gran número de expedientes al respecto, siendo esta población la más afectada por la destrucción de éstas industrias tras sucesivas ampliaciones y remodelaciones del entorno portuario y su influencia comercial en barrios como el de Santa Catalina, La Isleta y Guanarteme. Se ha tratado de suplir este déficit de documentos con el análisis de planos y ortofotos del servicio de cartografía oficial existentes, y el estudio a las islas de Tenerife, Gomera y Fuerteventura, para poder analizar de forma comparativa la relación entre la expansión urbana a las principales conurbaciones con la de la capital grancanaria. El procedimiento de estudio de la fotografía aérea evidenciaba con 
claridad proceso de crecimiento y desarrollo urbanístico, siendo las imágenes más antiguas de los años 1951-1957 y, a partir de ahí, tras la localización de los hornos, se intentó trazar los cambios y evolución de la trama urbana.

Las aportaciones bibliografías de diferentes autores y trabajos ha sido fundamental como referencia para valorar los antecedentes del tema de estudio, diferenciando fuentes históricas (QuinTANA, 2004; 2015), planteamientos etnográficos (SuÁreZ, 1994; Mireles, 2019), o estudios comparativos sobre tipologías de hornos de cal (MANZANo, 2018). Finalmente, a través del uso de la documentación anteriormente referenciada, se ha podido analizar el desarrollo «urbanístico de los hornos de cal en el contexto de las ciudades y su vinculación con el entorno inmediato, así como su afección al tejido urbano» (MANZANo y Mireles, 2020).

\section{ANÁLISIS TIPOLÓGICO Y ESQUEMA DE FUNCIONAMIENTO}

Los hornos de grandes proporciones, los de reverbero, que se ejecutaron en los contextos de las grandes urbes canarias abastecieron la demanda del sector de la construcción a finales del siglo XIX y primeras décadas del xx, fruto de la presión urbanística (MANZANo y Mireles, 2017). En relación a la localización tradicional de los hornos de cal, se ha rastreado su emplazamiento en base a tres criterios:

- Por su presencia cercana a terrenos calcáreos, muchos próximos a la zona costera, así como en los de Aguadulce, Telde o en El Cabrón, en Agüimes (RAMóN, 2003).

- Por ser factor de su ubicación ha sido la necesidad de agua, aspecto básico para poder convertir el carbonato cálcico en óxido de calcio tras su calcinación, para «apagarla o matarla»y, por último.

- La existencia de vías de comunicación que hubiesen facilitado el transporte hasta las zonas de comercialización. Es de hacer nota que, en las grandes obras hidráulicas, como las presas, los hornos de cal se hicieron junto a las infraestructuras, facilitando una gran producción ante la necesidad de levantar enormes muros de contención (GONZÁLEZ, 2008).

Desde el punto de las tipologías de hornos censados en el Archipiélago, sobresalen por el número de ejemplares que han permanecido, los hornos troncocónicos de mampostería (Hernández y PeRERA, 2003:47), que se levantaban en lugares elevados de la orografía donde, aprovechando un desnivel, se embutía la estructura de calcinación.

La cuba, generalmente de sección semioval, en su parte superior, por donde se cargaban desde su boca las piedras a calcinar y, dos bajo la cuba, el hogar, separado del anterior, por un sistema de perfiles metálicos horizontales o "parrilla» (SUÁreZ, 1994: 273).

Las paredes de estos hornos de cal no son rectas, sino que tienen la tendencia a levantarse con un ligero abombamiento en la zona central del paramento: «Exteriormente los hornos se ejecutaban con muros de mampostería de piedra careada o con muros cajón de piedra y mortero de cal y, el interior, mediante 
piedra muerta (piedra de molino, tobas volcánicas, etc.). Se cubría con una capa de barro y arena, en unos casos y en otros mediante ladrillos refractarios» (MANZANO, SERRANO y Díaz, 2018: 249).

La pendiente del terreno en el que se insertaba el horno, facilitaba el traslado de la piedra de la cal y el llenado por capas, de costras de caliche y carbón, a través de la boca de la cámara. En el lateral se encontraban las rampas que daban acceso a la parte superior cuando el terreno era llano, y el área de combustión, en la zona inferior, se separaba de la superior, a través de una rejilla, o listones de hierro paralelos, que sujetaban y permitían la quema de la materia prima facilitando la aireación del carbón.

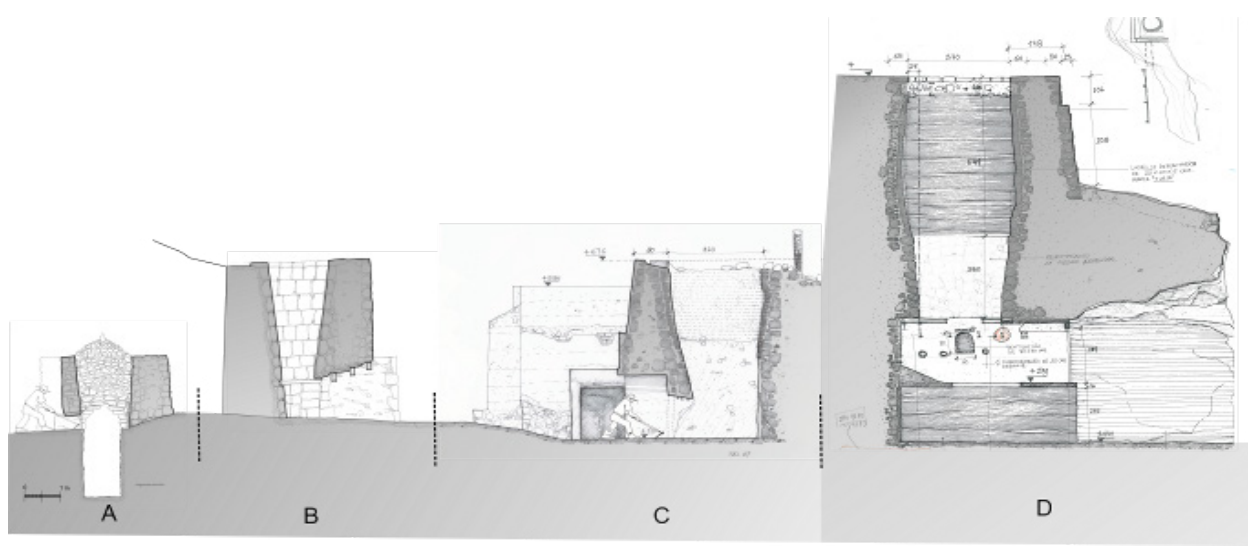

Figura 2. En esta figura se representa las distintas secciones de hornos que podemos encontrarnos en las islas, desde el horno o calera doméstica (A) hasta los de funcionamiento continuo con sección troncocónica (B) y la de sección de forma de tonel (C y D). Fuente. Elaboración propia.

La actividad de la cal tuvo su momento de mayor producción en siglos pasados, principalmente a finales del siglo XIX, por el capital que puso en movimiento la expansión de los cultivos de exportación, como el tomate o la platanera, que tenían un valor estratégico en el conjunto de las economías insulares al ser la base de la transformación del suelo agrícola de secano en regadío (QuintANA, 2015: 99).

Los hornos de reverbero, fue una tipología desarrollada a finales del siglo XIX en los núcleos urbanos de las principales ciudades del Archipiélago, principalmente en las islas capitalinas. Se caracterizan porque su producción era industrial, con un poder de transformación de caliche en cal, mayor que el de tipo tradicional troncocónico, y tenían una chimenea «de tiro» que en altura evacuaba los humos que producía para así evitar la afección a la población, transportando los gases a una altura superior. 


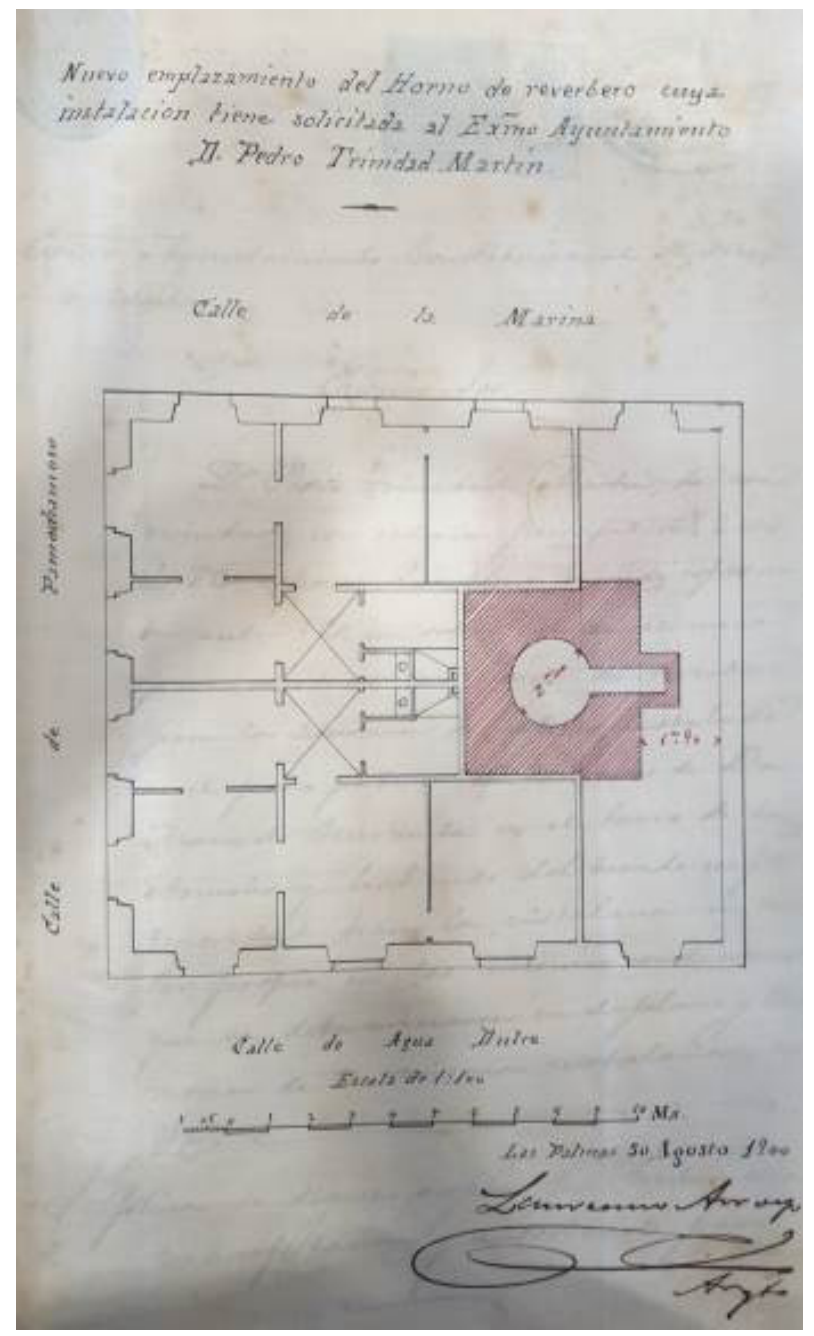

Figura 3. Planta de uno de los proyectos de hornos de cal reverbero, dentro de la edificación, año 1900. Los hornos se integran dentro del tejido urbano. Fuente: Archivo Histórico Provincial de Las Palmas.

En el contexto grancanario, la actividad portuaria desde finales del siglo XIX, propiciada por la declaración de puertos francos promulgada por Bravo Murillo en 1852, trajo como consecuencia un progresivo enriquecimiento de la burguesía urbana, que reinvirtió en la expansión del suelo urbano. Este crecimiento económico tuvo un reflejo evidente en la arquitectura civil en las primeras décadas del siglo xx de Las Palmas de Gran Canaria. La demanda de cal aumentó de tal forma que, las autorizaciones locales para la fabricación de hornos de mayores dimensiones 
se dispararon. Estos nuevos hornos buscaron un emplazamiento próximo a zonas portuarias con muelles, desde donde se abastecían de las materias primas (carbón y carbonatos cálcicos). Un ejemplo que ha pervivido son los hornos, de planta cuadrangular al exterior, de Risco Verde, en la playa de Arinaga, Agüimes, que describiremos: dimensiones de más de 10 metros de alto, y laterales que van de los 5 a los 20 metros, bocas comprendidas entre los 3 y 5 metros, y tolvas de hierro para mejorar la funcionalidad de las partes (SUÁREZ, 1994: 273-274). Se habilitaron en estos hornos y para mejorar su rendimiento accesos de tierra para que el camión pudiera cargar en la misma base, junto a la hornilla, cuando transportaba la materia prima en bruto desde el próximo muelle del faro de Arinaga.

A partir de la década de 1940 y hasta 1960, se produjo un repunte de la producción de cal en Canarias, debido al proceso autárquico que el país sufría tras la contienda de la Guerra Civil. En décadas anteriores ya llegaban a los puertos canarios el cemento, tipo Portland, que facilitaba por sus características y bajo coste, el abandono de los hornos menos rentables. A partir de la década de los años 60, tras la progresiva apertura económica al exterior y reanudación de las exportaciones, los hornos de cal prácticamente cayeron en desuso, siendo la escasa relevancia que tenía este sector industrial en la economía canaria.

La cal se dejó de utilizar en la expansión de las nuevas urbanizaciones aparecidas en las décadas finales del pasado siglo. El profesor Ramón Ojeda, en su tesis doctoral escribe sobre la destrucción progresiva de los hornos de cal, que «las industrias tradicionales han sido durante la historia reciente de Gran Canaria actividades complementarias y de carácter minoritario, que tenían su desarrollo, como norma general, amparadas en la agricultura y la ganadería» (RAMÓN, 2003).

\section{HORNOS DE CAL REVERBERO EN LAS PALMAS DE GRAN CANARIA}

Desde el punto de vista económico, la construcción del Puerto del Refugio en 1883, incentivó la producción de cal en hornos reverberos provocada por el aumento de obras públicas (FLORIDO, 1999: 361-362). La burguesía capitalina y de las principales ciudades de la Isla tuvieron un especial cuidado en el tratamiento de las fachadas mejorando el ambiente urbano de los principales barrios de la parte baja de una ciudad en crecimiento, provocado por un inusitado crecimiento económico, que trajo aparejado un aumento de la población y la expansión urbanística de la ciudad. Una de las principales causas de esta expansión fue la inversión de dinero extranjero (MARTín, 1995). El flujo de capital inglés, además del alemán, tuvo como resultado una creciente relación comercial con los principales puertos europeos, que fue repercutiendo poco a poco en el resto de los sectores de la población local.

En este contexto se produjo la instalación de hornos reverberos en los barrios anexos a la zona portuaria, fundamentalmente en los barrios de Los Arenales y La Isleta, (FLoRIDO, 1999). Hornos de cal de grandes dimensiones y producción, que dejaban a los tradicionales y artesanales troncocónicos, con un producto final de 
peor calidad, para el aprovechamiento local de sectores socio-económicos menos favorecidos o para el consumo de localidades pequeñas con una tipología de viviendas de autoconstrucción o en obras hidráulicas de pequeño tamaño para una agricultura de autoconsumo.

Después de la Guerra Civil Española (1936-39) y, en el periodo posterior a la Segunda Guerra Mundial, el periodo de la Autarquía (1939-1959), sufrido en España, trajo consigo que el país estuviera prácticamente cerrado al comercio internacional. La falta de recursos $\mathrm{y}$, sobre todo de materiales constructivos, alargó la vida de multitud de hornos de cal que abastecieron a la población isleña, produciéndose un repunte de la producción de cal que estimuló la apertura de nuevos hornos, antes abandonados, y el mantenimiento de otros que ya prácticamente no eran rentables (MIRELES, 2019), con una calidad final del hidróxido de calcio, o «cal apagada», inferior a la producida en los hornos de reverbero.

En el interior de la ciudad de Las Palmas de Gran Canaria, los hornos que se levantaron durante este periodo, se documentaron en los proyectos redactados por ingenieros y arquitectos locales, con características técnicas que los hacían mejores que los existentes, para así evitar molestias a los vecinos porque: «Los hornos de cal reverbero era una tipología usada dentro de las ciudades por ser las que "causan al vecindario menos molestias que una cocina económica", los humos, de escasa entidad, salían a bastante altura, por lo que no eran respirados por los vecinos». ${ }^{2}$

Expondremos ahora que el horno de reverbero es de planta cuadrada al exterior, de cinco metros de lado, y el interior de forma circular de dos metros de diámetro. Estructurado de tal forma que, la piedra a calcinar no estuviese en contacto con el combustible, sino con la llama y gases producidos por la combustión. Los alzados exteriores se ejecutaron con mampostería ordinaria de piedra y barro, siendo el espesor de los muros y fábricas, en la parte más débil, de metro y medio. El interior del horno y su bóveda, se construía con ladrillos refractarios en cierta parte de su espesor, y con ladrillos comunes en el resto. Entre el macizo exterior y la camisa o pared interna del horno, se dejaba un espacio bastante considerable de aproximadamente setenta centímetros $(70 \mathrm{~cm})$, en el cual se apisonaba arena, ceniza, arcilla o cualquier otro material, que fuese mal conductor, a fin de evitar la pérdida de calor por radiación.

Se estructuraban estos hornos en base a tres elementos esenciales: el hogar, el laboratorio y la chimenea:

1) El hogar, con un metro de altura, se encontraba separado del laboratorio por la parrilla, realizada en ladrillos, al que se unía un conducto con el exterior y sección recta de un metro de altura por sesenta centímetros de ancho por el cual se introducía la carga de combustible y se hacía la limpieza del hogar, al que se le colocaba un segundo emparrillado de hierro, a una altura del piso, para que

2 Extracto de la Memoria de la Solicitud de licencia «Relativo a la instalación de un horno reverbero para la calcinación de calizas en el patio interior de las casas de D. Manuel Miranda, sitas en el barrio de los Arenales por D. Pedro Trinidad Martín». Ayuntamiento de Las Palmas, Serie Edificios Industriales. Años:1869-1931. Nº inv.: 6 (Año 1900, Expdte.: 91, p.2). 
sirviera de cenicero.

2) El laboratorio, de forma cilíndrica, cubierto por una bóveda esférica, tenía tres metros de altura total en el vértice de la bóveda y en el que se abría el tragante por el cual se introducía la materia a calcinar, gracias a que la chimenea de palastro se articulaba en una plataforma sobre la boca del mismo tragante.

3) La chimenea tenía seis metros de altura, desde la boca inferior de dicho tragante hasta la zona de salida de humos y estaba provista, además, de un sombrero de coronación que recogía todos los productos sólidos de la combustión que pudieran ser arrastrados por el viento sobre las casas vecinas. También, para regular el tiro, al nivel de la boca alta del tragante, se abría un registro formado por una plancha giratoria metálica.

Los hornos se levantaron próximos al mar y, por su especial disposición, funcionaban como una hornilla herméticamente cerrada, sin más comunicación con el exterior que la chimenea de tiro que conducía los gases y humos a bastante altura, siempre hacia el mar, cualquiera que fuera el viento reinante. La capacidad de calcinación en cada hornada, era de ocho y medio a nueve metros cúbicos de caliza, usándose como combustible el carbón de hulla o antracita, a razón de unos tres hectolitros por metro cúbico de cal obtenida.

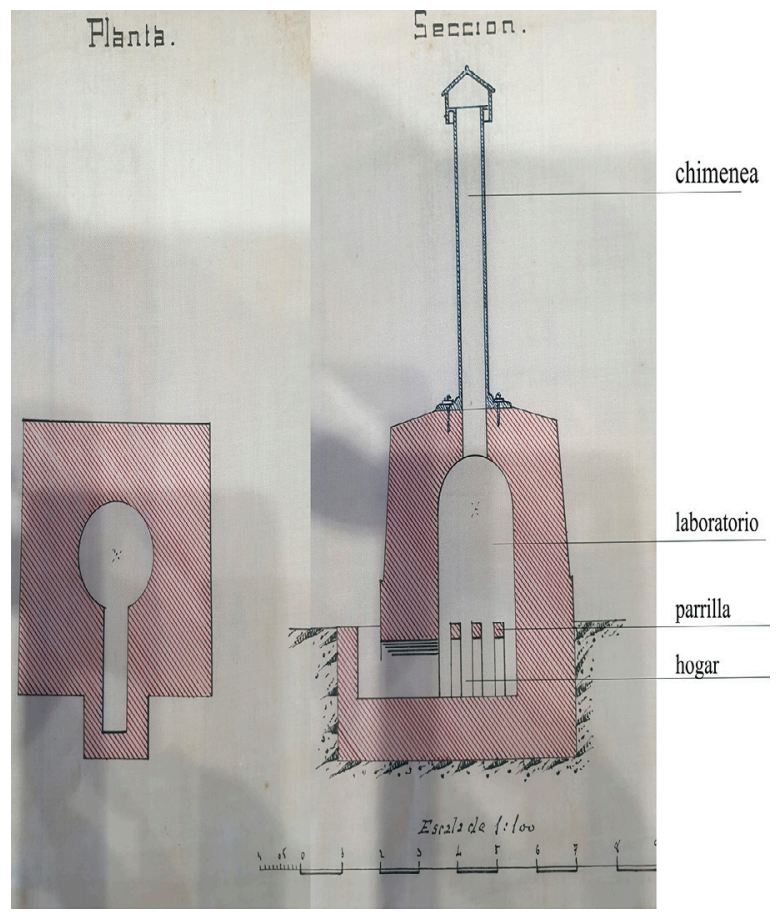

Figura 4. Planta y sección de un horno de cal reverbero. En la sección se indican los tres elementos principales de que se conforma el horno. Fuente: Archivo Histórico Provincial de Las Palmas. 
El sistema de funcionamiento de estas estructuras posibilitó su inserción dentro del tejido urbano y así se ha podido comprobar en los distintos proyectos que se presentaron en la ciudad de Las Palmas de Gran Canaria.

Entre los expedientes analizados en el Archivo Histórico Provincial de Las Palmas se deduce que, desde los inicios del siglo xx, y debido a la gran demanda dentro de la ciudad capitalina, se ejecutaron nuevos hornos que se situaron, en algunos casos, dentro de las mismas edificaciones existentes o colindantes a ellas. Muchos han desaparecido, otros aún se han podido encontrar dentro de la trama urbana en parcelas abandonadas con vientres rellenos de escombros, como los hornos del Pepe Conçalvez, que están en suelo urbano y el P. G. O. U. de las Palmas de Gran Canaria lo contempla dentro de la normativa en la categoría de Viviendas en Régimen de Protección (Vp).
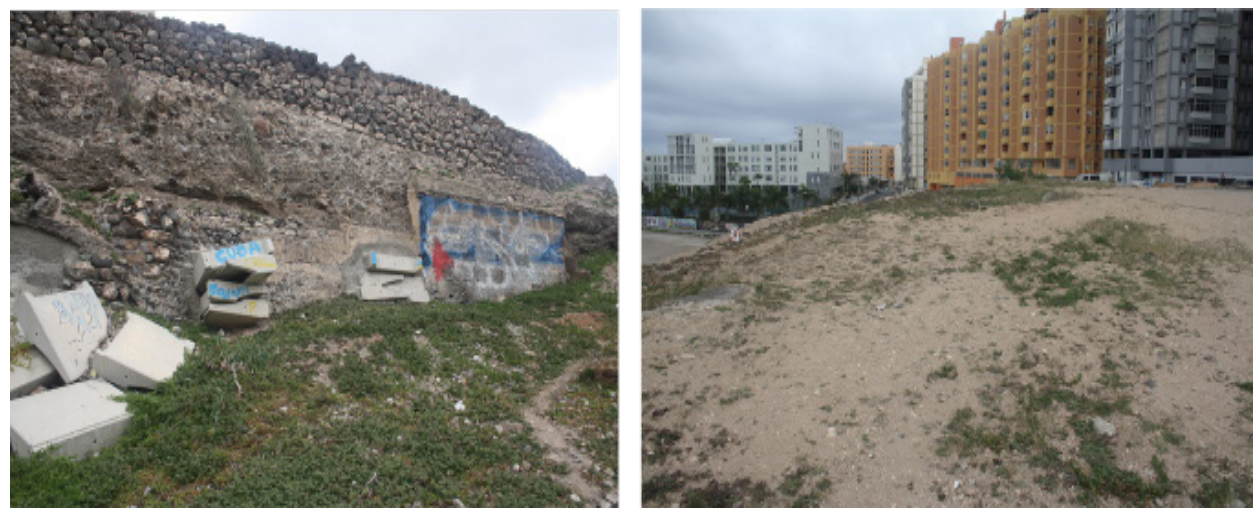

Figura 5. Hornos de cal en la zona del Pepe Conçalvez. Fotografías: Autores.

Pensamos que la restauración de los hornos ubicados en la proximidad del complejo deportivo Pepe Conçalvez potenciaría la rehabilitación y recuperación ambiental de la zona, en continuidad y remate con el espacio libre del Barranco de la Ballena ya que por el contrario la consecuencia de la construcción de viviendas protegidas, prolongaría un entorno degradado por la colmatación y saturación de bloques de viviendas. En el espacio libre que quedaba dentro de algunas edificaciones, en la zona del patio, se llegaron a introducir hornos de cal, como muestra el plano adjunto (Figura 6) del arquitecto Laureano Arroyo. 

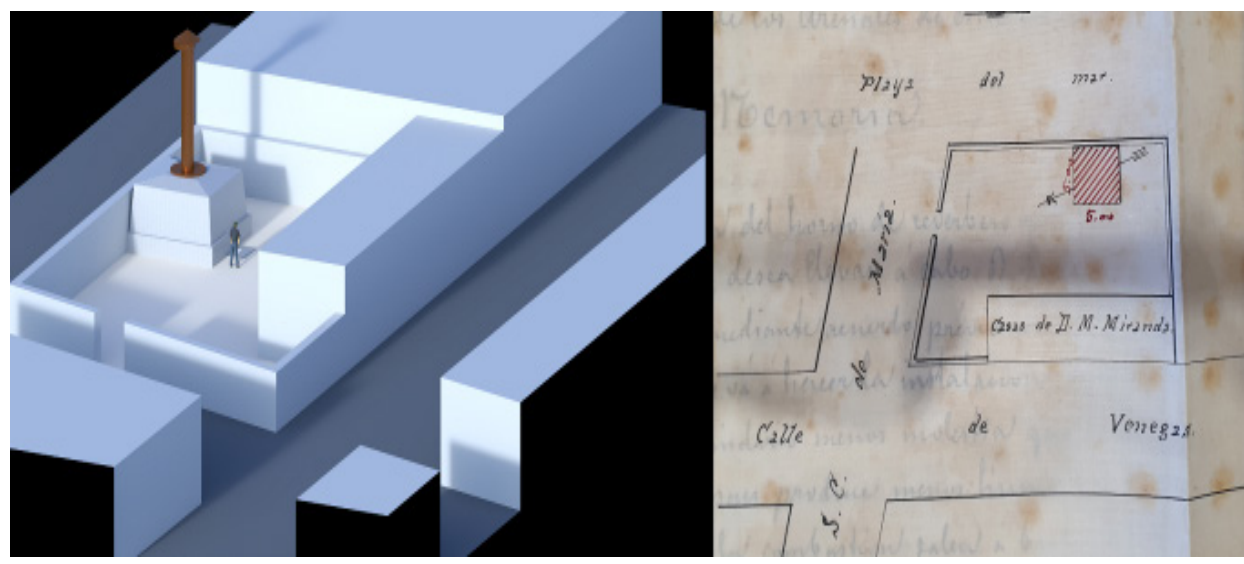

Figura 6. Esquema volumétrico de la situación del horno de cal, dentro de la edificación y plano de emplazamiento del horno de cal en la edificación. Fuente: Elaboración propia (izqda.) y Archivo Histórico Provincial de Las Palmas (dcha.).

A través de las licencias de obras expedidas para la apertura de hornos de cal por las autoridades de la provincia de Las Palmas, se detalla en la tabla adjunta (Tabla 1), que se acompaña, los dibujos de las infraestructuras, así como de la memoria descriptiva, firmada por un técnico cualificado.

TABLA 1

Licencias para la construcción de hornos de cal en Las Palmas de Gran Canaria

\begin{tabular}{|c|c|c|c|c|}
\hline Año & Propietario & Situación & Expediente & $\begin{array}{l}\text { Arquitecto / } \\
\text { Ingeniero }\end{array}$ \\
\hline 1900 & Pedro Trinidad Martín & $\begin{array}{l}\text { Agua Dulce } \\
\text { (Los Arenales) }\end{array}$ & $\begin{array}{l}\text { Relativo a la instalación de } \\
\text { un horno reverbero para la } \\
\text { calcinación de calizas en el patio } \\
\text { interior de la casa de D. Manuel } \\
\text { Miranda, sitas en el barrio de los } \\
\text { Arenales por D. Pedro Trinidad } \\
\text { Martín. }\end{array}$ & L. Arroyo \\
\hline 1901 & Bartolomé Díaz Díaz & Camino de Chil & $\begin{array}{l}\text { Instruido a instancia de Don } \\
\text { Bartolomé Diaz y Diaz pidiendo } \\
\text { autorización para la rehabilitar } \\
\text { é instalar de nuevo un horno de } \\
\text { cal en el margen izquierdo de la } \\
\text { carretera o camino de Chil }\end{array}$ & L. Arroyo \\
\hline
\end{tabular}


Jorge L. Manzano Cabrera y Francisco M. Mireles Betancor

\begin{tabular}{|c|c|c|l|c|}
\hline 1901 & Francisco Sepúlveda & Venegas & $\begin{array}{l}\text { Sobre instalación de un horno } \\
\text { reverbero para calcinación de } \\
\text { calizas, en un solar en la calle } \\
\text { de Venegas por D. Francisco } \\
\text { Sepúlveda }\end{array}$ & L. Arroyo \\
\hline 1901 & Pedro Trinidad Martín & $\begin{array}{c}\text { Playa Las } \\
\text { Arenas (junto } \\
\text { al mar) }\end{array}$ & $\begin{array}{l}\text { Relativo a la instalación de } \\
\text { un horno de reverbero para } \\
\text { la calcinación de calizas en un } \\
\text { solar que linda con la playa de } \\
\text { los Arenales de esta ciudad, } \\
\text { solicitada por D. Pedro Trinidad } \\
\text { Martin. }\end{array}$ & L. Arroyo \\
\hline 1904 & Pedro Trinidad Martín & $\begin{array}{l}\text { Pamochamoso } \\
\text { (Los Arenales) }\end{array}$ & $\begin{array}{l}\text { Relativo a la instalación de } \\
\text { un horno de reverbero para } \\
\text { la calcinación de calizas en un } \\
\text { solar que linda con la playa de } \\
\text { los Arenales de esta ciudad, } \\
\text { solicitada por D. Pedro Trinidad } \\
\text { Martin. }\end{array}$ & Cirilo \\
Moreno \\
\hline
\end{tabular}

Fuente. Elaboración propia.

En la figura anexa (Figura 7), se han representado dos tipos de hornos, según los planos que solicitaron licencia de obras en Las Palmas de Gran Canaria. El primer plano, fechado en 1901, correspondía al horno ubicado en la carretera de Chile, en el margen izquierdo, en la conocida como calle de «El Horno de Cal». El segundo plano de 1904, que se levantaría en Los Arenales, entre las calles Pamochamoso y la antigua calle de La Marina -hoy Luis Doreste Silva-, dibujaba un horno de características diferentes al primero. La lectura de los planos se ha complementado con las ortofotos de 1951-1957, y los fotogramas aéreos de 19511957. En azul se ha recalcado la ubicación de los hornos anteriormente reseñados. Es de señalar que, en las imágenes se ha podido constatar que del horno de la zona del complejo deportivo Pepe Conçalvez, aún permanecían restos y vestigios de su existencia en una parcela de suelo urbano.

Los hornos de Las Palmas de Gran Canaria calcinaban las piedras de cal importadas, esta era una de las grandes diferencias con la mayoría del resto de estructuras documentadas en el interior y resto de la isla. Los hornos de reverbero eran de grandes dimensiones y respondían a la iniciativa de inversión privada, contando por lo general con proyecto y planos elaborados por un ingeniero o arquitecto local, frente a los hornos troncocónicos que eran resultado de la experiencia y observación acumulada por la población local de un recurso explotado artesanalmente (MANZANO y MirELES, 2017: 129). 

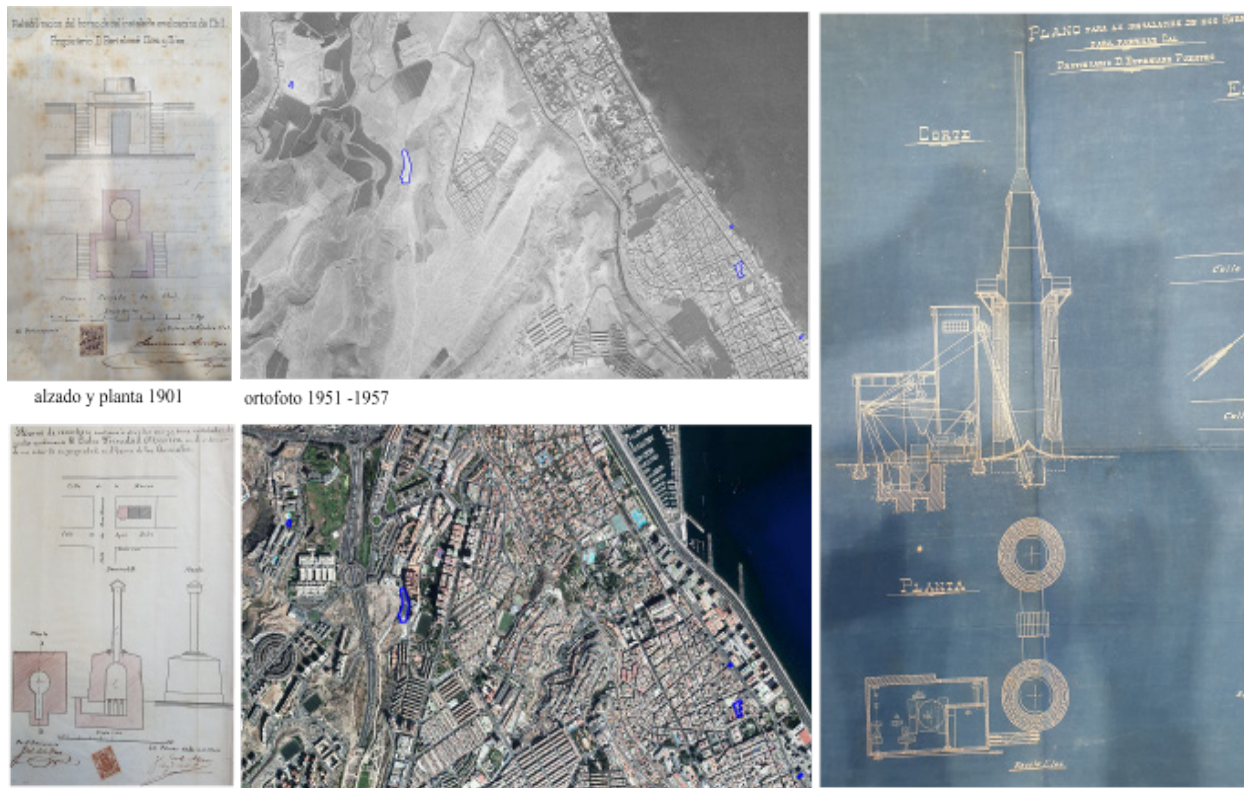

planta, sección y alzado 1904 fotograma 2019

planos de dos homos de cal, 1924

Figura 7. Planos de los hornos diseñados por Laureano Arroyo y Cirilo y la de dos hornos propiedad de D. Eufeniano Fuentes, en 1924 y fotogramas señalizándose la situación de los hornos en la ciudad de Las Palmas de Gran Canaria. Fuente: Archivo Histórico Provincial de Las Palmas y Grafcan.

Estos hornos de reverbero formaban parte de la trama urbana (Figura 4), pues se diseñaron para estar integrados dentro o anexos a una edificación o vivienda, como se recoge en la memoria y planos de Laureano Arroyo o de Cirilo Moreno. En la actualidad, la totalidad de estos hornos han desaparecido por la presión urbanística, quedando aún algunos restos de otras tipologías, como el referido del Pepe Conçalvez que se encuentra a la espera de la formalización las normas urbanísticas para su total destrucción.

\section{HORNOS SINGULARES EN LA PROVINCIA DE TENERIFE}

El Puerto de la Cruz, en Tenerife, posee un conjunto industrial de finales del siglo XIX, formado por cuatro hornos de cal, con unas instalaciones anexas para el tratamiento y almacenamiento del material de obra producto de la calcinación, que ha sido declarado, por sus características tipológicas e históricas, como BIC, en 2009, en calidad de Sitio Etnológico (BOC, 2009/071, de 15 de abril). En la zona denominada por el topónimo Las Cabezas, en la zona alta del casco urbano, su 
autor el maestro albañil, Gregorio Barreto levantó una serie de estructuras, tres mayores para la quema de rocas calcáreas y caliches y, una cuarta, mas reducida que los anteriores, para la producción de yeso. Entre las peculiaridades que singularizaban estos bienes del patrimonio industrial, estaba la incorporación como parte fundamental de las "tanquillas», que almacenaban el agua que "apagaba» la cal viva para convertirla en "cal muerta» y poderla manipular, al que se anexaban unos almacenes, a modo de cobertizos, para guardar el carbón de la cocción y, otro, para el yeso.

Tenerife ha sido deficitaria tradicionalmente de costras calcáreas y caliches (HERnÁNDEZ, 2011:31), por lo que estos hornos, ubicados en las proximidades del núcleo portuario del Puerto de La Cruz (Hernández, 2011: 28), han aprovechado el transporte marítimo que recalaba en sus costas para trasladar los frutos de los cultivos de exportación de la platanera del valle de La Orotava, para llevar como lastre en sus bodegas las piedras de cal, preferiblemente de Fuerteventura, que luego, una vez depositadas en la orilla, se trasladaban a lomos de bestias a la parte alta de la localidad. ${ }^{3}$

El conjunto de hornos estuvo funcionando hasta el primer cuarto del siglo xx. El uso de cemento como material para los morteros se fue generalizando con posterioridad a la Primera Guerra Mundial, como ingrediente primordial de la construcción de estructuras «a cajón». A este factor se le unió que la mejora en la navegabilidad de la flota mercantil fue prescindiendo del lastre las piedras de cal.

Los motivos de la incoación de un expediente primero y su posterior declaración como elemento singular del patrimonio histórico canario de éstos elementos arquitectónicos, no estaba basada únicamente en sus características estructurales, estéticas e históricas, sino en la fuerte presión urbanística que la zona alta del Puerto de la Cruz había sufrido. La declaración como BIC obligó a las instituciones públicas a su protección y a organizar un entorno de seguridad del bien cultural, así como la redacción de un plan especial donde se detallaban los espacios para el uso y disfrute del público, a través de una oferta cultural para la población local y foránea.

Los hornos de Las Cabezas estaban, además, afectados por un nudo de tráfico próximo, así como por el emplazamiento de un centro escolar adyacente, cuyos escombros habían sepultado parte de la superficie de ellos, deviniendo en un lamentable estado de fragilidad causado por la precaridad de su conservación, que ponía en riesgo su permanencia y que aumentaba la posibilidad de su desaparición. La restauración realizada por la administración pública no solamente ha recuperado el aspecto original de los hornos, sino que ha respetado y recuperado los vestigios de los caminos empedrados, así como las tanquillas y los muros que, mediante anastilosis, se han vuelto a levantar con las piedras y materiales primigenios.

La rehabilitación del bien cultural ha conllevado un conjunto de intervenciones urbanísticas que han facilitado la comunicación de espacios y áreas. La edificación

3 Portal Cabildo de Tenerife: Hornos de Cal - Puerto de la Cruz [en línea]. Disponible en: https:// www.tenerife.es/portalcabtfe/es/site_content/50-patrimonio-historico/3310-hornos-de-cal-puertode-la-cruz-bic1193?preview=1\#m\%C3\%A1s-informaci\%C3\%B3n [Consulta: 12/07/2020]. 
del puente peatonal que conecta con la calle Blanco ha propiciado la accesibilidad de los visitantes que desde el centro de la ciudad quieran acceder al área sociorecreativa. La actuación se remató con una empalizada que ha servido de aislamiento y protección a la fuerte presión que tráfico rodado ha ejercido en las décadas anteriores a la declaración como BIC.
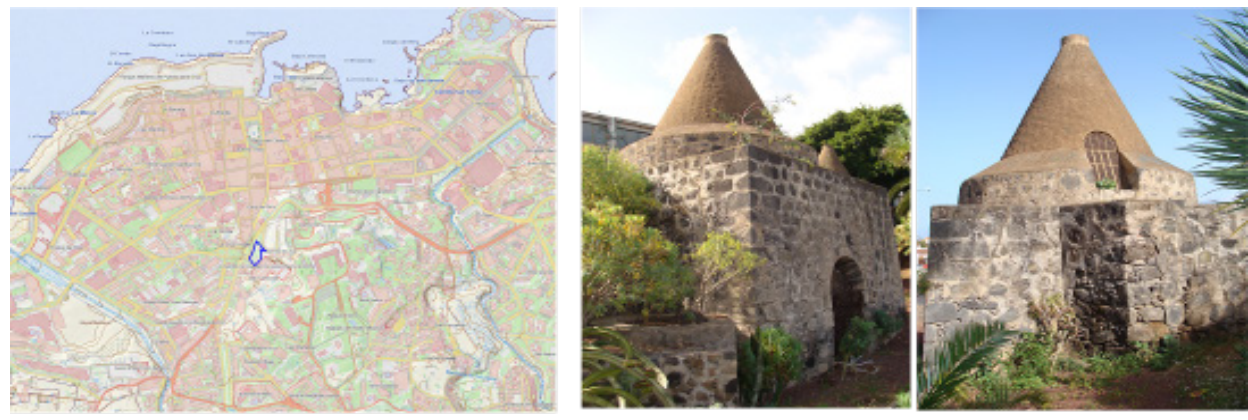

Localización

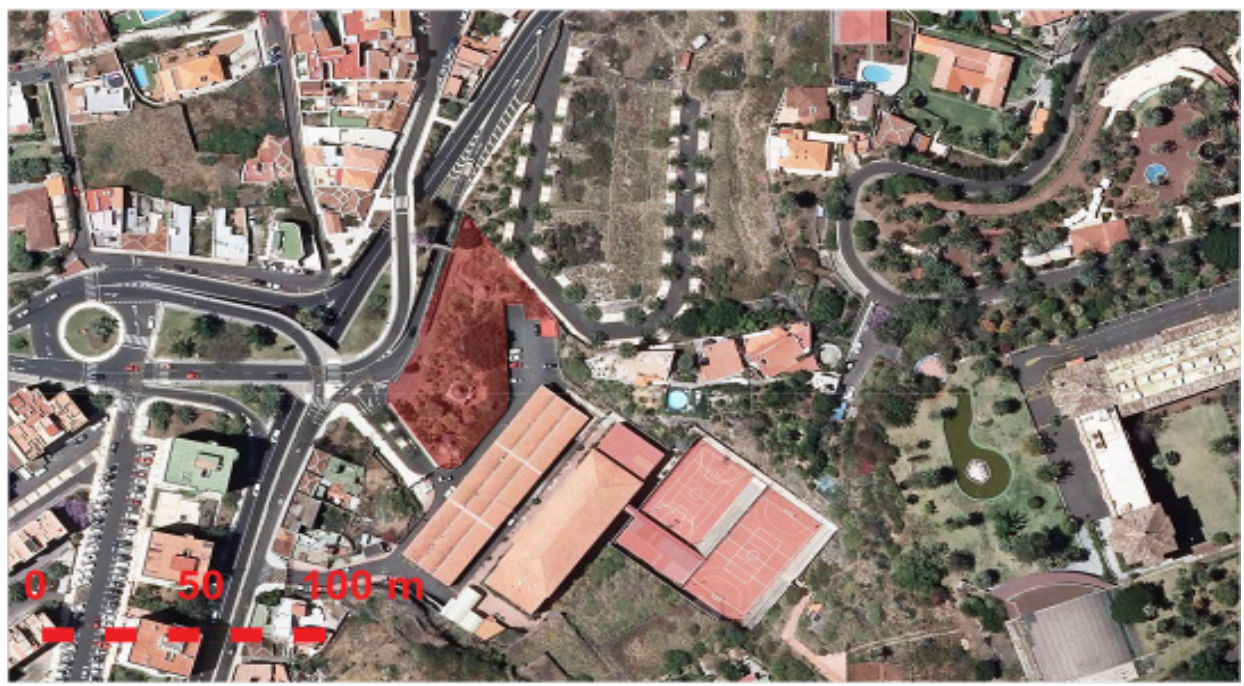

ortofoto año 2019

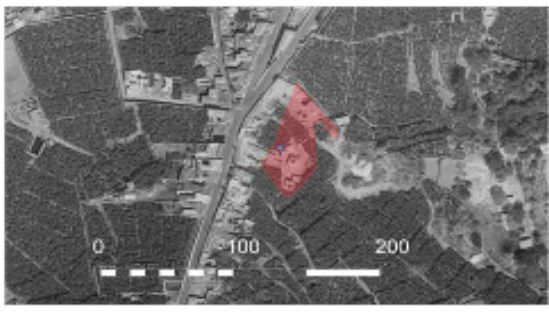

ortofoto aho 1951-195?

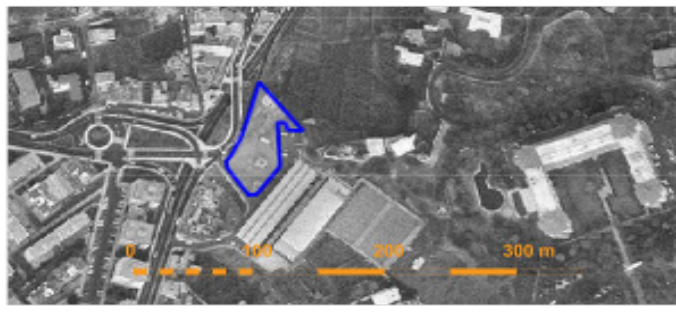

ariaforo ato 198 ?

Figura 8. Localización y Ortofotos del horno de cal del Puerto de la Cruz, 1951-1957 /1987 /2019. Fotografías de los hornos: Autores. Fuente: Grafcan. Elaboración propia. 
En La Gomera, próximo al centro urbano de San Sebastián, orientado al suroeste, se ha localizado un horno industrial entre La Pista de La Palmita, en dirección a Hermigua, y la calle Avda José Aguiar, detrás del campo de fútbol. A una altitud de $30 \mathrm{~m}$., se compone por un muro de contención de cajón, sobresaliendo a mitad del mismo de forma circular, de 6 metros de diámetro y de 10 metros de altura. Las dimensiones de la base rectangular del horno son de 22 metros de largo por $18 \mathrm{~m}$ de ancho, salvando un desnivel de 10 metros. El horno circular y escalonado ha sido construido por sillares rojos, con dos bocas en la base y, en los laterales donde el horno se abre, formando medio hexágono.

Esta ha sido la única estructura de calcinación, u horno de cal, que tenemos conocimiento en la isla de la Gomera y que se encontraba funcionando en la primera mitad del siglo xx. Hasta la actualidad se ha mantenido en una parcela que no ha sido afectada por la transformación y crecimiento urbanístico de la capital gomera (Figura 9).

En el año 2014, debido a su estado de deterioro y por los efectos devastadores de unas lluvias torrenciales, se produjo el desmoronamiento de la esquina de la terraza inferior que da a la vía pública.

El horno de cal, que se encontraba en estado de abandono y en una situación de conservación pésima, ha requerido de una intervención arquitectónica inmediata. Su excelente situación dentro de una parcela aislada, a dos niveles y en un entorno urbano que no ha sido alterado, ha posibilitado la integración en el tejido urbano y la revalorización, tras su rehabilitación, del contexto habitable. Ejemplos de la recuperación del entorno se ha podido encontrar en las intervenciones de los elementos BIC, como son los hornos de Fuerteventura, en Puerto del Rosario y en La Guirra, o los de La Cabeza, en el Puerto de La Cruz, Tenerife.

Este horno en la capital gomera ha contado con todos los elementos para poder ser un elemento del patrimonio industrial que se integrarara dentro de la trama urbana, tras el reacondicionamiento del espacio y la puesta en valor de este elemento etnográfico y del patrimonio industrial más significativos de la isla de La Gomera. 

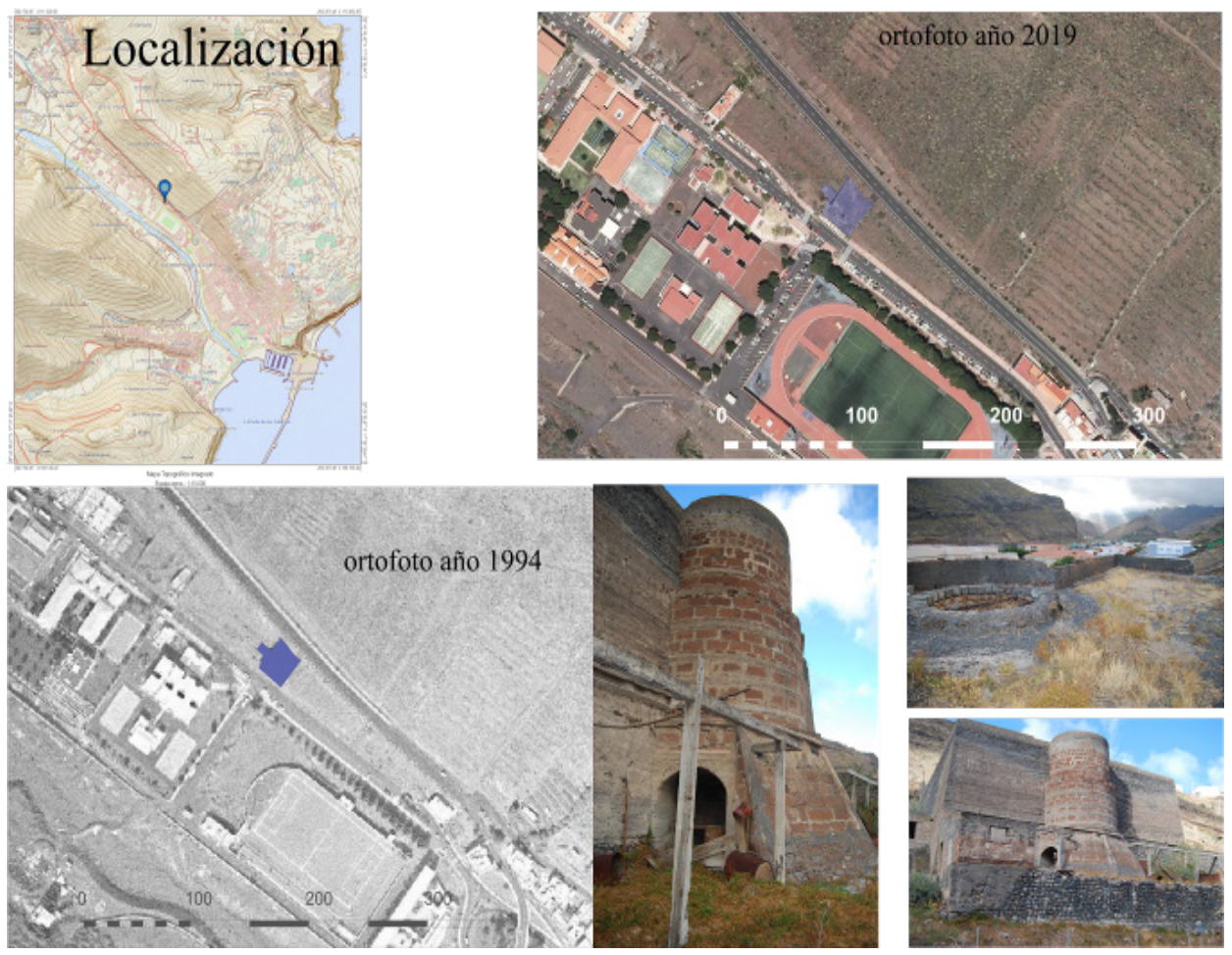

Figura 9. Localización y Ortofotos del horno de cal de San Sebastián de la Gomera. Fuente: Grafcan. Elaboración propia.

\section{LOS HORNOS DE CAL EN PUERTO DEL ROSARIO, FUERTEVENTURA}

La extracción y producción de cal, al menos se ha remontado al siglo XVII en la isla de Fuerteventura, al igual que en Lanzarote (LoBO y QuiNTANA, 1997: 25), que registran el mayor número de caleras y de hornos en la actualidad. Predominan las fábricas de tipología doméstica para la producción de cal destinada al consumo local (CÁRDENAS et al., 2007:147), así como algunas estructuras de calcinación industriales (HERNÁNDEZ y RODRÍGUEZ, 1993:18). Se ha inventariado más de 300 unidades, y ha sido, junto a Tenerife, la isla que ha tenido un mayor patrimonio industrial asociado a la actividad económica de la cal. Desgraciadamente muchos hornos han sido fagocitados por la trama urbana y han desaparecido o se han reutilizado con otra finalidad, sin embargo, otros han sido protegidos como el conjunto de hornos de La Guirra, agrupación industrial formada por tres hornos, un almacén, una caseta-vivienda y un aljibe, en el término municipal de Antigua, en la denominada con el topónimo de Caleta de la Guirra, desembocadura del Barranco de Miraflor. Estas unidades han sido declaradas en 1999, Bien de 
Interés Cultural, con categoría de Monumento, así como el grupo de hornos de cal del Puerto del Tostón de El Cotillo, en Antigua, también protegidos como Bien de Interés Cultural, con categoría de Sitio Etnológico, (BIC) en el año 2019. Otras estructuras fueron recuperadas y se pusieron en funcionamiento, como la experiencia de 1995 en la que «el Cabildo ha explotado un horno de carbón en Tesjuate, con el fin de utilizar este aglomerante para obras de restauración, tales como: «La Alcogida», en Tefía, «Las Salinas del Carmen», «El Palmeral de Lajares», dando unos resultados excelentes también en obras de nueva planta, mezclada con arena y cemento en morteros «bastardos» para recibido de piedras y enfoscados (RodríGuez, 1995:10).

En el casco de Puerto del Rosario y sus alrededores se ha podido ubicar los principales hornos. Los de La Hondura, pertenecientes a don Antonio Bordón, que desde los años veinte ya quemaban cal. Otros, propiedad de don Carlos Suárez, que poseía diversos hornos en la Guirra, Antigua, se localizaban junto a la actual potabilizadora. Los últimos hornos de gran volumen que se construyeron en Fuerteventura fueron los de don Isaac González Luis, más conocido por don Federico, «el rey de la cal» (RodríGueZ, 1999:55).

Durante el proceso de calcinación, la transformación química genera humos (monóxido de carbono), que puede afectar a la población y viviendas próximas, y fue una de las causas por las que en 1946, los hornos situados en las inmediaciones del Charco se compensan con el traslado a Los Berrieles, por las molestias que producían las emisiones a las viviendas militares, gracias a una subvención del mando Económico. Junto a la Charca se encontraban los de don Jacinto Lorenzo y en Risco Prieto los hornos de don Manuel Castañeyra. Al igual que estas grandes entidades, se conservaban aún otras de menor tamaño que, por la necesidad de agua de esta industria, haría que la mayoría se ubicasen junto al mar.

Este conjunto del Charco, en Puerto del Rosario, ha sido objeto de una intervención urbanística y, en la actualidad, la zona recuperada se ha rehabilitado espacialmente (FLORIDO, 2018: 69-70), debido a su protección patrimonial. La restauración de estos vestigios ha sido un factor clave para la revitalización comercial, así como un modelo a seguir para revalorización de muchas de las edificaciones históricas existentes en el contexto (Figura 10). 
Evolución de los hornos de cal a través del tiempo en las ciudades de Canarias
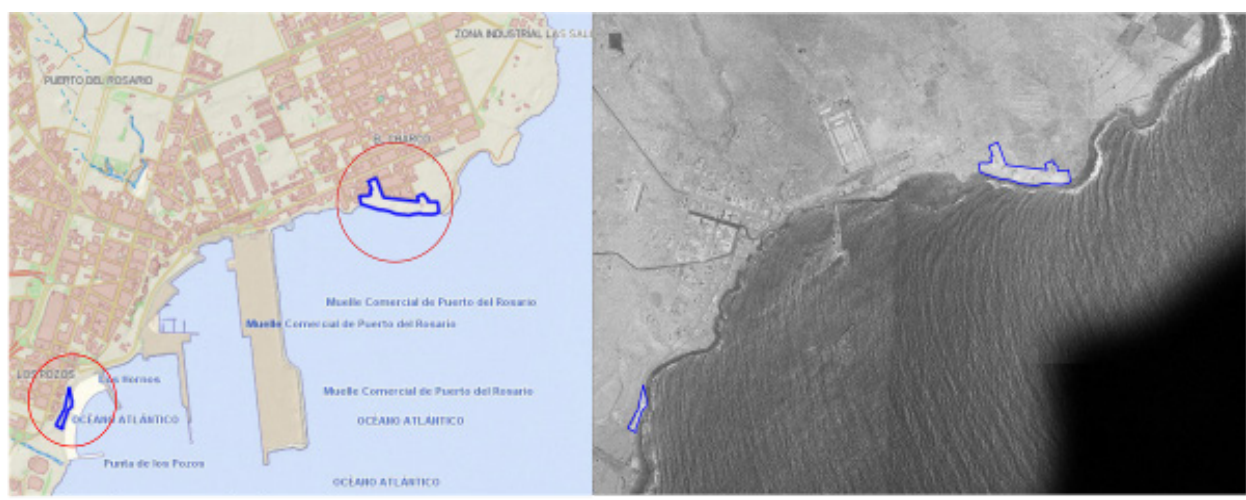

Localización - Puerto del Rosario

Vista aérea de los homos. 1951 - 1957

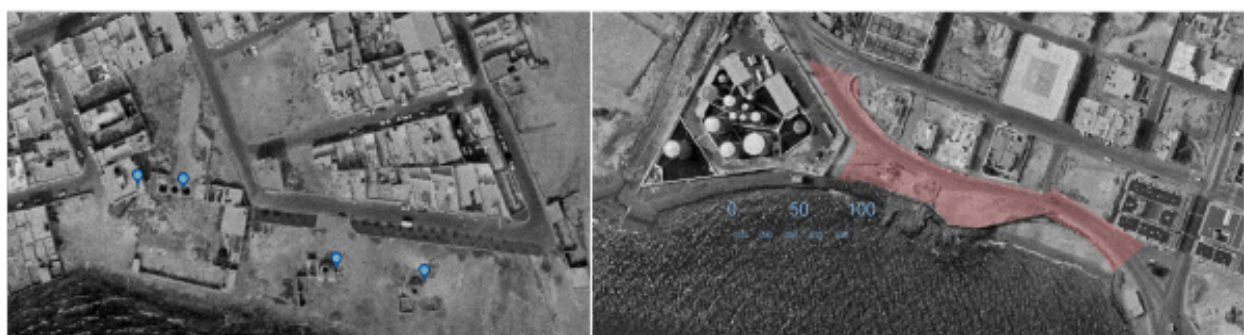

ortofoto 1994
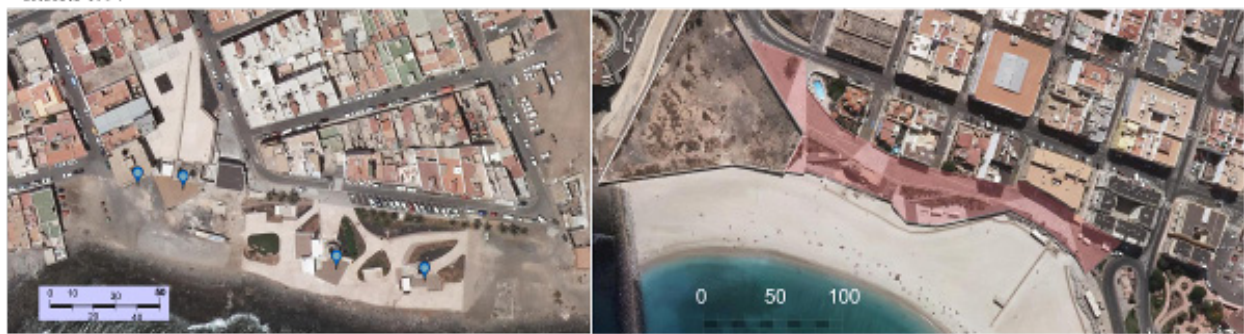

fotograma 2019
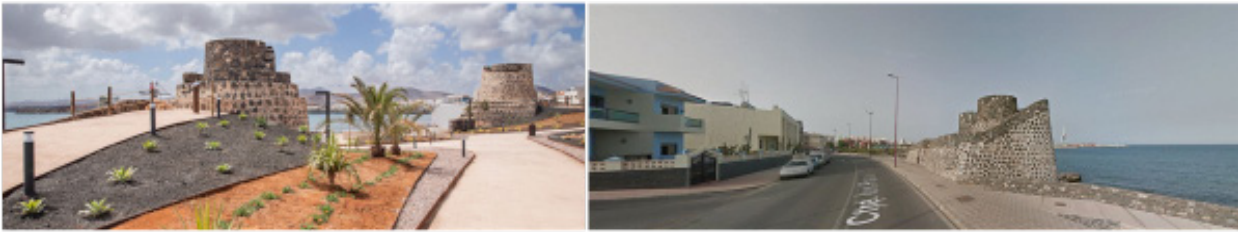

Vista de has hornos. Diario de Fuerteventura. 2019

Figura 10. Localización y Fotografías aéreas y vista de los hornos del Charco. Puerto del Rosario, Fuerteventura. Fuente: Grafcan. Elaboración propia.

En las imágenes anteriores, se puede apreciar la positiva transformación que ha generado la rehabilitación de los hornos y de su entorno. La restauración y puesta en valor de este patrimonio industrial no se entiende, en este caso, sin el influjo de esa intervención en su entorno inmediato, afectando de manera eficaz a la trama urbana y, por lo tanto, al desarrollo del tejido urbano. 


\section{CONCLUSIONES}

La revisión bibliográfica y documental de la producción de cal y los caleros en Canarias, ha evidenciado dos aspectos. Por un lado, el deficiente tratamiento que los hornos de reverbero han tenido en los estudios que se han publicado y, por otro, que este patrimonio ha sido estudiado de forma aislada, sin profundizar en el factor de transformación del entorno y en el contexto urbano y poblacional.

El estudio de los hornos de cal reverberos (estructura, formación y evolución) ha abierto una nueva vía de investigación en la incidencia social y económica. La comparación de las imágenes del territorio inmediato vinculado a este tipo de industrias y su efecto con el urbanismo, ha revelado la importancia del patrimonio industrial como eje transformador de áreas urbanas en las principales capitales del Archipiélago.

Las nuevas directrices que la legislación ha impuesto a la restauración de edificaciones históricas en general, y al patrimonio industrial en particular, hacen que, cada vez más, se direccione al sector de la rehabilitación en el respeto por los componentes y elementos originales en los proyectos de recuperación espacial urbana. La actual coyuntura de protección de los bienes patrimoniales ha incentivado a los investigadores a profundizar en los materiales, morteros y tipologías constructivas, así como en las industrias que sustentaron la base de las edificaciones de pasadas generaciones. Los morteros que se emplearon en las edificaciones durante expansión urbanística de las ciudades canarias a finales del siglo XIX y primeras décadas del $x x$, ha sido un ejemplo del reto al que se debe enfrentar la arquitectura patrimonial en la actualidad.

Este artículo ha permitido un nuevo enfoque al introducir una tipología industrial del patrimonio inmueble, como los hornos de cal en el modelo urbano, como factor generador y vector desencadenante de la recuperación del paisaje. Algunos de los conjuntos de calcinación que han quedado integrados y en relación al entramado urbanístico de las ciudades donde se hallan, han provocado una positiva impronta, desde múltiples perspectivas, en el tejido urbano, mejorando la calidad y habitabilidad de estos espacios que conocemos.

La revalorización de los hornos como factor cultural, y el interés que su protección ha incentivado en la sociedad, ha sido un factor estructural que ha generado una modificación sustancial de la trama urbana y en el contexto próximo y que, a su vez ha redundado en los espacios de uso lúdico y cultural. De esta forma, se ha producido una «devolución social» de unas áreas rehabilitadas para esparcimiento del ciudadano, resultante de la integración paisajística en la malla con elementos históricos circundante a través de la positiva transformación del contexto inmediato.

El horno de cal, presente en el paisaje costero, rural desde hace siglos en el Archipiélago, no ha sobrevivido en muchos casos por encontrarse en las zonas de expansión de nuestras ciudades por el desarrollo de nuevas edificaciones a partir de mitad del siglo xx. Algunos conjuntos de hornos, han modificado su uso formando parte de las edificaciones, como aljibes, cuadras, o para usos turísticos mientras que otros, han sido devorados por la presión urbanística. 
En los casos en los que se han salvaguardado estas construcciones industriales, una vez protegidas y restauradas, han pasado a formar parte del tejido urbano, enriqueciendo e influenciando en su entorno, como así ha quedado patente en las actuaciones urbanísticas que se han llevado a cabo en los hornos de Las Cabezas en Puerto de la Cruz, en Tenerife; en El Charco para la isla de Fuerteventura, la intervención en la zona de Risco Verde, en la avenida de Arinaga, Gran Canaria, con la transformación en museo y restaurante, o el de La Palmita en San Sebastián de La Gomera. En las edificaciones que persisten sin que hayan mediado actuaciones tendentes a su recuperación, como elementos del patrimonio cultural propio, debiéramos tomar partido.

\section{REFERENCIAS}

De Cárdenas, J.; Maldonado, L.; Gil, I.J. (2007): Arquitectura popular de Lanzarote, Fundación Diego de Sagredo, Madrid.

Florido, A. (1999): Arqueología industrial en Las Palmas de Gran Canaria, Ediciones del Cabildo de Gran Canaria, Las Palmas de Gran Canaria.

Florido CASTRO, A. (2000): «El patrimonio arquitectónico industrial en la capital de Gran Canaria: un tesoro por valorar», en F. Morales (coord..), Actas del XIII Coloquio de Historia Canario-Americana, Cabildo de Gran Canaria, Las Palmas de Gran Canaria: 2901-2910.

Florido CAstro, A. (2018): Patrimonio Histórico Industrial de Fuerteventura. Gobierno de Canarias, Dirección General de Patrimonio Histórico.

Gil, B.; PeñA, C.J.; Fernández, M.A. (2006): «Hornos de Cal», en I Congreso Internacional de Patrimonio e Historia de la Ingeniería, Universidad de Las Palmas de Gran Canaria, Las Palmas de Gran Canaria: 83-104.

HernándeZ, A.J.; QuintanA, P.C.; JiméneZ, A.M. (2020): «La producción de materiales constructivos en Canarias durante los siglos XVI, XVII y XVIII: el caso de la cantería tradicional de Arucas (Gran Canaria, Islas Canarias)», en E. Acosta (coord.) Actas del XXIII Coloquio de Historia Canario-Americana, Cabildo de Gran Canaria, Las Palmas de Gran Canaria: 060.

Hernández, F.M. (2011): Apuntes sobre el patrimonio etnográfico de Tenerife, Asociación Cultural «Pinolere. Proyecto Cultural», La Orotava.

Hernández, A.S.; Perera, M.A., dir. (2003): La villa de Teguise, Cabildo de Lanzarote, Lanzarote.

Hernández, F.; Rodríguez, M.D. (1993): «Hornos de cal (caleras) en Lanzarote», Aguayro, 204: 15-18.

GonzÁlez, J. (2008): Construcción de la presa las cuevas de las Niñas en Majada Alta. Gran Canaria, 1930-1958, Comunidad de Regantes de la Presa de la Cueva de las Niñas, Las Palmas de Gran Canaria.

Lobo CABrera, M. (2004): «Los comienzos de la industria de la cal en Canarias», en C. Díaz y M. Morera (coord.), Homenaje a Francisco Navarro Artiles, Academia Canaria de la Lengua, Cabildo Insular de Fuerteventura, Puerto del Rosario: 
273-288.

Lobo Cabrera, M.; Quintana Andrés, P. (1997): Arquitectura de Lanzarote en el siglo XVII. Documentos para su historia, Cabildo de Lanzarote, Arrecife.

Manzano Cabrera, J.L. (2015): Los hornos de cal en Gran Canaria. Historia, evolución y tipología, Tesis doctoral inédita, Universidad de Las Palmas de Gran Canaria, Las Palmas de Gran Canaria.

ManZANo, J.; Mireles, F. (2017): «Incidencias de la cal en el paisaje tradicional de Gran Canaria», El Pajar: Cuaderno de Etnografía Canaria, 32: 121-139.

Manzano, J.; Mireles, F. (2020): «La presencia de los hornos de cal en la configuración de los espacios urbanos de las ciudades de Canarias», en XV Coloquio de Geografía Urbana, Universidad de Las Palmas de Gran Canaria, Las Palmas de Gran Canaria.

Manzano, J.; Serrano, J.; Díaz, I. (2018): «Tres hornos de cal en la isla de Gran Canaria. Tipologías y funcionamiento», en J.I. Álvarez Galindo et al. (eds.), Tradición, versatilidad e innovación en la cal: un material de excelencia. Actas de las VI Jornadas FICAL, Universidad de Navarra, Pamplona: 283-295.

Martin, J. (1995): «Ingeniería en Canarias, 1850-1900: Juan de León y Castillo», Boletín Millares Carlo, 14: 88-91.

Mireles, F. (2019): «El ingeniero Juan de León y Castillo y el uso hidráulico de la cal», en I Jornadas de Cultura del Agua, Casa Museo León y Castillo, Telde.

Mireles, F. (1996): «En torno a la Cal», Guía Histórico Cultural de Telde, 8: 43-44.

QuintanA ANDRÉs, P. (2015): «El hábitat rural en Gran Canaria: una breve aproximación histórica» en Arquitectura y Paisaje. La Arquitectura tradicional en el medio rural de Canarias, Tomo III, Rincones del Atlántico, 9, Santa Cruz de Tenerife: 8-293.

QuintanA Andrés, P. (2010): «La casa cubierta vegetal en Canarias: tipologías constructivas, uso social y evolución histórica», El Pajar: Cuaderno de Etnografía Canaria, 28: 34-41.

QuintANA ANDRÉs, P. (2004): «La vivienda popular en Canarias durante el Antiguo Régimen», El Museo Canario, 59, 319-349.

Ramón, A. (2003): Carta Etnográfica de Gran Canaria, Tesis doctoral inédita, Universidad de Las Palmas de Gran Canaria, Las Palmas de Gran Canaria.

RodríGuez, A. (1999): «La cal de Fuerteventura», El Pajar: Cuaderno de Etnografía Canaria, 5: 53-56.

RodríGuez, A.; De Armas, I. (1995): «La cal en Fuerteventura», Aguayro, 211: 7-13.

SuÁrez, F. (2018): Arqueología Industrial en Canarias, Cabildo Insular de Gran Canaria, Las Palmas de Gran Canaria.

SuÁrez, F. (1994): Ingenierías históricas de La Aldea, Cabildo Insular de Gran Canaria, Las Palmas de Gran Canaria. 
